\title{
0 que nos ensinam e o que aprendem os alunos de EJA em seus processos educativos? Contribuições da educação popular
}

\section{What teach and learn students of EJA in their educational process? Popular education contributions}

\section{¿Qué nos enseñan y aprenden los alumnos de la EJA en sus procesos educativos? Contribuciones de la Educación Popular}

Keila Mourana Marques Silva ${ }^{1}$

Valéria Oliveira de Vasconcelos ${ }^{1}$

DOI: http://dx.doi.org/ 10.20435/serie-estudos.v22i45.1007

\begin{abstract}
Resumo: O presente trabalho trata de uma pesquisa de mestrado em Educação Sociocomunitária na qual foram investigadas as concepções de 76 alunos acerca do ensinar e do aprender na Educação de Jovens e Adultos (EJA I - anos iniciais) em relação ao seu papel como educandos, ao papel do/a professor/a, à educação, à escola, entre outras. A partir desses dados, buscamos levantar possíveis mediações da Educação Popular (EP). Para a coleta de dados, utilizamos como suporte um questionário com perguntas geradoras a partir de referencial teórico específico, que foi socializado e problematizado em rodas de conversa. Os resultados apontaram aproximações entre as concepções dos participantes e algumas premissas da Educação Popular, tais como: participação, autonomia e emancipação. A EP preconiza que, mais que levar em conta a realidade do educando, devemos partir dela, trabalhando com atividades significativas que contribuam para a construção de conhecimentos, mediatizadas pelo diálogo. Muito embora alguns considerem que as questões levantadas nessa investigação estejam superadas e/ou ultrapassadas, nossas experiências empíricas, nossos aportes teóricos e os resultados da pesquisa indicam que a reflexão sobre a prática educativa e a necessária humanização dos processos pedagógicos persistem como uma exigência fundamental e urgente na Educação de Jovens e Adultos.
\end{abstract}

Palavras-chave: processos educativos; EJA; educação popular.

Abstract: This study is a master's research in socio-communitarian education in which we investigated the conceptions of 76 students about teaching and learning in the Youth and Adult Education (EJA) in relation to its role as learners, the teacher's role, education, school, among others. From these data

${ }^{1}$ Centro Universitário Salesiano de São Paulo (UNISAL), Americana, São Paulo, Brasil. 
we seek to raise possible contributions from Popular Education (EP). To collect the data we used to support a questionnaire with generating questions from specific theoretical framework, which was socialized and questioned in conversation circles. The results showed similarities between the views of the participants and some assumptions of Popular Education, such as: participation, autonomy and emancipation. The EP, more to take into account the reality of educating, should be based on the same reality, working with meaningful activities that contribute to the construction of knowledge, mediated by the dialogue. While some consider that the issues raised in this research are overcome and / or exceeded, our empirical experience, the theoretical support and the results of the research indicate that the reflection on educational practice and the necessary humanization of pedagogical processes persist as a fundamental and urgent requirement in the Youth and Adult Education.

Key words: educative processes; EJA; popular education.

Resumen: El presente trabajo trata de una investigación de maestría en Educación Socio comunitaria en la que se investigaron las concepciones de 76 alumnos acerca de la enseñanza y el aprendizaje en la Educación de Jóvenes y Adultos (EJA I- años iniciales) en relación a su papel como educandos, al papel del (de la) profesor/a, a la educación, a la escuela, entre otras. A partir de esos datos, buscamos levantar posibles mediaciones de la Educación Popular (EP). Para la recolección de datos, utilizamos como soporte un cuestionario con preguntas generadoras a partir de referencial teórico específico, que fue socializado y problematizado en ruedas de conversación. Los resultados apuntaron acercamientos entre las concepciones de los participantes y algunas premisas de la Educación Popular, tales como: participación, autonomía y emancipación. La EP preconiza que, más allá de que tener en cuenta la realidad del educando, debemos partir de ella, trabajando con actividades significativas que contribuyan a la construcción de conocimientos, mediatizadas por el diálogo. Aunque algunos consideran que las cuestiones planteadas en esta investigación están superadas y/o sobrepasadas, nuestras experiencias empíricas, nuestros aportes teóricos y los resultados de la investigación indican que la reflexión sobre la práctica educativa y la necesaria humanización de los procesos pedagógicos persisten como una exigencia fundamental y urgente en la Educación de Jóvenes y Adultos.

Palabras clave: procesos educativos; EJA; educación popular.

\section{INTRODUÇÃO}

Esse artigo advém das reflexões, análises e resultados emergidos de uma pesquisa de Mestrado em Educação Sociocomunitária desenvolvida no Programa de Mestrado em Educação do Centro Universitário Salesiano de São Paulo (UNISALCampus Maria Auxiliadora/Americana, SP), na qual investigamos algumas concepções sobre os processos de ensinar e aprender a partir dos olhares de alunas e alunos participantes do primeiro ciclo da Educação de Jovens e Adultos (EJA I).

A Educação de Jovens e Adultos envolve uma problemática que, historicamente, vem desafiando os/as profissionais da área comprometidos com uma prática educativa problematizadora. Acreditamos que nós, educadores, devemos criar condições no processo ensino/aprendizagem que tornem a busca do conhecimento uma experiência significativa e que, através dela, ensinemos e aprendamos junto com os/as estudantes, valorizando a experiência vivenciada de maneira contextualizada, reflexiva 
O que nos ensinam e o que aprendem os alunos de EJA em seus processos educativos?

Contribuições da educação popular

e autônoma. Por mais que essas ideias pareçam superadas, nossa experiência prática mostra que a Educação de Jovens e Adultos ainda permanece fortemente atrelada a práticas autoritárias e verticalizadas.

Como afirma Paulo Freire (1996), jamais podemos perder a esperança em construir uma educação melhor, e, para que isso aconteça, devemos refletir sobre nossa prática, sobre as atividades desenvolvidas e como elas veêm sendo utilizadas, uma vez que estas podem tanto levar à submissão, à conformação com a realidade, como também à transformação desta.

Cabe a nós, educadores, contribuir para reavivar no educando a curiosidade epistemológica, a busca pelo conhecimento, para que compreenda melhor sua visão de mundo, sua realidade e, assim, construa uma consciência de que é capaz de fazer as próprias escolhas como sujeito, e não mais como objeto.

Nenhuma formação docente verdadeira pode se fazer alheada, de um lado, do exercício da criticidade que implica a promoção da curiosidade ingênua à curiosidade epistemológica, e do outro, sem o reconhecimento do valor das emoções, da sensibilidade, da afetividade, da intuição ou adivinhação. Conhecer não é, de fato, adivinhar, mas tem algo que ver, de vez em quando, com adivinhar, com intuir. O importante, não resta dúvida, é não pararmos satisfeitos ao nível das intuições, mas submetê-las à análise metodicamente rigorosa de nossa curiosidade epistemológica. (FREIRE, 1996, p. 20).

De acordo com a proposta de Freire, a Educação de Jovens e Adultos deveria ter como substrato a condição mesma dos educandos, de modo a problematizar suas vivências cotidianas e encontrar caminhos para superar as condições de opressão. 0 aluno, nessa perspectiva, é visto como capaz de se perceber como agente de sua própria história e, portanto, capaz também de modificá-la. As propostas de Freire ainda representam um grande desafio para a educação como um todo e para a Educação de Jovens e Adultos particularmente. Acreditamos que as diferentes concepções sobre os processos do ensinar e do aprender podem, por vezes, gerar um distanciamento entre professores e alunos, interferindo na construção do conhecimento. É comum o/a aluno/a não participar dessa construção por crer que quem sabe é o/a professor/a, e este, por sua vez, em muitas situações, confirma tal ideia.

Em função disso, emergem muitos questionamentos sobre como superar as chamadas "práticas bancárias". Conforme Freire (1987), o caminho para um trabalho de libertação a ser realizado pela liderança revolucionária não é a "propaganda libertadora". Não está no mero ato de "depositar" a crença da liberdade nos oprimidos, pensando assim em conquistar a sua confiança, mas sim no dialogar com eles/as e, 
conjuntamente, encontrar caminhos de emancipação. Nós, educadoras e educadoras, precisamos estar cientes de que o convencimento dos oprimidos de que estes devem lutar por sua libertação não é doação que se Ihes faça alguns "ilustrados", mas resultado de sua conscientização.

Nas formas de educação - que atualmente é preconizada por uma pretensa "Escola sem partido" - baseadas na transmissão de conhecimentos de um professor que sabe a um aluno que não sabe, é negada sua participação efetiva na construção do saber. Como antítese à educação bancária, Freire (1987) trará a concepção de educação libertadora que, mais tarde, vai se consolidar com o nome de Educação Popular, tendo claro que essa corrente pedagógica latino-americana emerge de muitos pilares em nosso continente (TORRES CARRILLO, 2008).

Na Educação Popular, é de extrema relevância valorizar cada situação de forma particular, estabelecendo vínculos de partilha e cooperação, auxiliando e respeitando educandas e educandos, ouvindo suas expectativas com vistas à conquista de autonomia, numa contínua busca pela emancipação.

Acreditamos que a Educação Popular pode contribuir para reacender "a chama da esperança" das classes populares, pois propõe uma relação educativa que vai além do trabalho com conteúdos escolares, vai em busca da formação do homem-pessoa, ao invés de homem-coisa, do homem como um ser social comprometido com as causas de seu tempo, insatisfeito, curioso, sonhador, esperançoso e fundamentalmente transformador. (PEREIRA; PEREIRA, 2010, p. 74).

Segundo tais autores, na medida em que acreditamos no potencial humano e estimulamos a participação de todas as pessoas, a Educação Popular transforma-se em um laboratório de experimentação conjunta, em vários níveis de atuação, que vão se fazendo presentes. Com isso a/o aprendiz encontra meios de experimentar sua capacidade de pensamento, argumentação e criação.

É importante ressaltar que, como afirmam Vasconcelos e Oliveira (2009, p. 136), ao falarmos de Educação Popular, "não estamos nos referindo àquela das classes populares, mas à educação com as classes populares, com elas compromissadas e com elas realizadas, mediante o diálogo".

\footnotetext{
2 Segundo Frei Betto, a proposta da "Escola Sem Partido" é impedir que os/as professores/as, principalmente os de Educação Básica, eduquem seus alunos com consciência crítica. Para o autor está claro que nenhum educador comprometido com a formação discente defende uma escola partidária na qual, por exemplo, todos se mostrem simpatizantes ou filiados a um determinado grupo. Não temos dúvida, concordando com o autor, de que não faz sentido a escola se aliar a um partido político, muito menos, por outro lado, pretender que não existem disputas de poder, um dos pilares da democracia.
} 
Assim, reitera-se que é imprescindível o desenvolvimento de reflexões para uma prática transformadora na EJA, por meio das quais, educadoras e educadores podem e devem desenvolver, junto com os/as educandos, novas formas de agir e de pensar. Além disso, através de distintas possibilidades de aprendizagem, pode-se rever o papel da escola nesse processo diante das inúmeras alternativas de ensino.

A educação vista sob o prisma da Educação Popular pode apontar algumas mediações na construção de conhecimentos e reflexões no sentido de um processo educacional mais humanizado, pautado no diálogo, no respeito, na confiança e no contínuo processo com vistas à emancipação, para a consecução de transformações sociais.

\section{METODOLOGIA}

Partindo dessas premissas, desenvolvemos uma pesquisa de mestrado em Educação Sociocomunitária buscando responder à seguinte questão: Quais são as concepções de alunos de instituições de EJA I sobre os processos de ensinar e aprender?

Para responder a ela, elencamos os seguintes objetivos: Levantar as concepções de alunos de EJA sobre os processos de ensinar e aprender; compreender aspectos dessas concepções (entendimento sobre o ser humano, a relação professor-aluno, a metodologia e a avaliação; entre outros); e analisar as possíveis mediações da Educação Popular.

Participaram da pesquisa 76 alunos (de oito salas em seis escolas) de uma fundação municipal da cidade de Campinas, SP (FUMEC), todas as pessoas integrantes do programa EJA Profissões. Para a coleta de dados foi aplicado um questionário contendo oito questões e cinco alternativas sistematizadas a partir de abordagens de teorias relacionadas ao processo de ensino e aprendizagem, seguindo o referencial de Mizukami (1986).

A escolha por esse referencial se deu em virtude de a autora citada organizar de maneira bastante sistematizada e didática, algumas das principais abordagens de ensino. Esse livro, considerado já clássico por alguns da área de educação, não dá conta de todas as abordagens de ensino, entretanto, tece um excelente panorama de algumas das principais concepções correntes ainda hoje. Esse recorte não significa que entendamos a educação e suas relações como compartimentos estanques e que estes representem a totalidade da compreensão sobre seus processos. Durante a coleta de dados para a pesquisa de que tratamos nesse artigo, percebemos a necessidade de elaborar um instrumento de investigação coerente com o público-alvo 
a que se dirigia e que suas percepções pudessem ser abarcadas em categorias bem demarcadas.

Para Mizukami (1986), toda concepção referente ao fenômeno educacional, determinada teoria/proposta ou abordagem do processo ensino e aprendizagem, privilegia um ou outro aspecto educacional. A autora, por meio de seus estudos, aponta cinco abordagens que, segundo seu entendimento, mais parecem ter motivado os/ as professores/as ao longo de suas vidas, são elas: Tradicional, Comportamentalista, Humanista, Cognitivista e Sociocultural. Segundo a pesquisadora, tais abordagens influenciam na formação do/a professor/a e em como este se posiciona frente ao fenômeno educacional. A análise de cada abordagem foi realizada, na pesquisa de que trata o presente trabalho, a partir da compreensão de ser humano, professor-aluno, metodologia e avaliação, muito embora a autora tenha se dedicado, em sua obra, a analisar um repertório mais amplo do que este.

De acordo com Mizukami (1986), em linhas gerais, no ensino tradicional, o/a professor/a é o que tudo sabe, possui informações e as transmite para seus alunos que ainda não sabem, tudo depende dele que detém conhecimento a ser transmitido. Na abordagem comportamentalista, o ser humano é considerado como produto do meio, que pode ser manipulado e controlado, enfatizando-se a questão do método, o que ensinar e em que nível se quer que o/a aluno/a aprenda, buscando estímulos para que o educando responda de acordo com os objetivos pré-fixados. Em ambas as abordagens, o/a professor/a é quem define o conteúdo a ser transmitido. Não há flexibilidade e o ensino é diretivo. Nas abordagens cognitivista, humanista e sociocultural há algumas características que as aproximam. Na abordagem cognitivista, a ênfase é a participação ativa do/a aluno/a no curso de sua aprendizagem, o desenvolvimento das operações, das relações existentes e o conhecimento envolvido durante o processo de ensino e aprendizagem. Na abordagem humanista e na sociocultural, a importância do desenvolvimento humano, tomando como base a questão social, cultural e econômica dos estudantes, no decorrer da aprendizagem, é o seu principal foco.

Reiterando, temos claro que a escolha por esse recorte trouxe limites e possibilidades para a investigação, uma vez que não há uma teoria fechada, única. Por outro lado, esse procedimento permitiu estabelecer alguns parâmetros bem delimitados, que foram cotejados com a teoria na análise dos resultados.

Conforme o exposto, elaboramos um questionário com oito questões, cada uma das cinco alternativas possíveis que dizia respeito a uma abordagem específica, 
segundo o citado referencial de Mizukami (1986), e foram organizadas de maneira aleatória, em cada uma das oito questões, para que os/as respondentes não identificassem um padrão recorrente de respostas, segundo essa ou aquela abordagem.

As questões e respectivas alternativas estão arroladas abaixo:

1. O que você acha que tem que fazer, como ALUNO, para aprender melhor?

\begin{tabular}{|l|l|}
\hline & $\begin{array}{l}\text { O aluno vai aprender se ele tiver interesse, independentemente do/a professor/a } \\
\text { e da escola; }\end{array}$ \\
\hline $\begin{array}{l}\text { Buscar novos conhecimentos, pensando sobre o que aprendeu e compartilhando } \\
\text { com os/as colegas; }\end{array}$ \\
\hline $\begin{array}{l}\text { Somente se o/a professor/a forçar a aprendizagem, mostrando o que é melhor } \\
\text { para os/as alunos/as por meio de modelos a seguir; }\end{array}$ \\
\hline $\begin{array}{l}\text { Construir sua aprendizagem, a partir do que você já sabe, através de materiais } \\
\text { diversos (da escola e de fora dela); }\end{array}$ \\
\hline $\begin{array}{l}\text { Ele aprende por etapas, que devem ser avaliadas por meio de provas, testes e } \\
\text { notas. }\end{array}$ \\
\hline
\end{tabular}

2. Como você gostaria que fosse a ESCOLA?

\begin{tabular}{|l|l|}
\hline & $\begin{array}{l}\text { Um lugar que controle todos os/as alunos/as, ensinando o jeito certo, premiando } \\
\text { quem se comporta melhor; }\end{array}$ \\
\hline $\begin{array}{l}\text { Um lugar em que o/a aluno/a possa aprender e ensinar, junto com os/as professo- } \\
\text { res/as, com muita conversa e respeito dos dois lados; }\end{array}$ \\
\hline $\begin{array}{l}\text { Um ambiente desafiador, que ajude o/a aluno/a a aprender por si mesmo, através } \\
\text { de pesquisas, leituras, }\end{array}$ \\
\hline $\begin{array}{l}\text { O lugar ideal para aprender; quanto mais sério melhor para os/as alunos/as não } \\
\text { se distraírem. }\end{array}$ \\
\hline $\begin{array}{l}\text { Um lugar que respeite os/as alunos/as, que todos possam dizer o que pensam, } \\
\text { descontraído e sem nenhuma pressão. }\end{array}$ \\
\hline
\end{tabular}

3. Como o/a professor/a deve trabalhar em sala de aula, na sua opinião?

\begin{tabular}{|l|l|}
\hline & O professor é quem decide o que e como ensinar para os/as alunos/as; \\
\hline $\begin{array}{l}\text { Com muitas atividades planejadas e reforço para verificar se o/a aluno/a realmen- } \\
\text { te aprendeu; }\end{array}$ & \begin{tabular}{l} 
Com um estilo próprio para facilitar a aprendizagem do/a aluno/a, sem pressão; \\
\hline $\begin{array}{l}\text { O professor deve propor desafios para os/as alunos/as e apresentar problemas } \\
\text { sem dar a resposta pronta; }\end{array}$
\end{tabular} \\
\hline $\begin{array}{l}\text { O professor deve criar condições para que juntos, professor e aluno construam o } \\
\text { conhecimento através de conversas e reflexões. }\end{array}$ \\
\hline
\end{tabular}


4. De que forma você acredita que poderia melhorar tanto as maneiras de ensinar quanto de aprender na escola:

\begin{tabular}{|l|l|}
\hline $\begin{array}{l}\text { O professor tem que cobrar as lições dos/as alunos/as, dar reforço se for preciso, } \\
\text { fazer avaliações quantas vezes forem precisas até que o/a aluno/a aprenda; }\end{array}$ \\
\hline $\begin{array}{l}\text { Os alunos devem aceitar a verdade: fazer o que o/a professor/a manda, afinal é } \\
\text { ele quem sabe o que é melhor para seus alunos, ele estudou para isso; }\end{array}$ \\
\hline $\begin{array}{l}\text { O professor deve respeitar o que o/a aluno/a sabe, desenvolvendo suas potencia- } \\
\text { lidades por meio de atividades adequadas a cada um; }\end{array}$ \\
$\begin{array}{l}\text { É o/a aluno/a que tem que se responsabilizar por aprender de acordo com seus } \\
\text { interesses. O professor não tem que cobrar do/a aluno/a, impor regras; }\end{array}$ \\
$\begin{array}{l}\text { O professor deve criar maneiras para que o/a aluno/a aprenda, conversando e } \\
\text { questionando, buscando contribuir para transformar sua realidade. }\end{array}$ \\
\hline
\end{tabular}

5. Como você acha que deve ser a avaliação?

\begin{tabular}{|l|l|}
\hline $\begin{array}{l}\text { Pela autoavaliação, pois devemos ter responsabilidade sobre nossas aprendiza- } \\
\text { gens; }\end{array}$ \\
\hline $\begin{array}{l}\text { Além de provas, testes, chamadas orais, o/a professor/a avaliar por meio de elo- } \\
\text { gios e prêmios àqueles/as que apresentarem melhor desempenho; }\end{array}$ \\
\hline $\begin{array}{l}\text { A avaliação conjunta professor/aluno, sempre, contínua do que acontece nas salas } \\
\text { de aula e na vida; }\end{array}$ \\
\hline $\begin{array}{l}\text { A avaliação deve ser livre, por meio de escrita espontânea, expressões, textos dos/ } \\
\text { as alunos/as; }\end{array}$ \\
\hline Por meio de provas, testes, chamadas orais e muitos exercícios. \\
\hline
\end{tabular}

\section{Para você o conhecimento:}

\begin{tabular}{|l|l|}
\hline & $\begin{array}{l}\text { É construído a partir da experiência individual e ajuda a transformar a vida, tor- } \\
\text { nando as pessoas melhores; }\end{array}$ \\
\hline & $\begin{array}{l}\text { É transmitido através da escola, quanto mais armazenadas e acumuladas as infor- } \\
\text { mações mais inteligentes ficam as pessoas. }\end{array}$ \\
\hline $\begin{array}{l}\text { É uma nova descoberta para o indivíduo. O que ele aprende leva a uma maior } \\
\text { competência, a partir de experiências planejadas; }\end{array}$ \\
\hline $\begin{array}{l}\text { É considerado uma construção contínua, em etapas de formação até um estado } \\
\text { de equilíbrio que nunca é alcançado por completo; }\end{array}$ \\
\hline $\begin{array}{l}\text { É construído pelas pessoas para que entendam melhor sua realidade, pensem } \\
\text { sobre ela e, possam transformar sua história. }\end{array}$ \\
\hline
\end{tabular}


7. Para você o que a educação deveria priorizar:

\begin{tabular}{|l|l|}
\hline & $\begin{array}{l}\text { Pensar sobre a realidade, provocando e criando condições para que se desenvolva } \\
\text { uma atitude de reflexão crítica, comprometida com a ação; }\end{array}$ \\
\hline A instrução, caracterizada pela transmissão de conhecimentos pela escola; \\
\hline $\begin{array}{l}\text { Condições para que o/a aluno/a aprenda por si próprio e conquiste autonomia } \\
\text { intelectual, desenvolvendo sua personalidade; }\end{array}$ \\
\hline $\begin{array}{l}\text { A valorização da autonomia, da iniciativa, da responsabilidade, da autodetermina- } \\
\text { ção, e a aprendizagem de coisas que servirão para a solução de seus problemas. }\end{array}$ \\
$\begin{array}{l}\text { A promoção de mudanças desejáveis e permanentes no indivíduo, adquirindo no- } \\
\text { vos comportamentos e modificando os comportamentos indesejados. }\end{array}$ \\
\hline
\end{tabular}

8. Em relação ao ensinar e o aprender, o importante é:

\begin{tabular}{|l|l|}
\hline $\begin{array}{l}\text { Conseguir o diploma e boas notas de acordo com o conteúdo transmitido levan- } \\
\text { do-se em conta o ritmo de cada aluno e de acordo com os objetivos estabelecidos; }\end{array}$ \\
\hline $\begin{array}{l}\text { Aprender independentemente de conteúdos, mas a escola deverá possibilitar } \\
\text { ao/a aluno/a o desenvolvimento de suas potencialidades por meio de jogos, leitu- } \\
\text { ras, discussão, arte, oficina etc. }\end{array}$ \\
\hline A ação e reflexão dos homens sobre o mundo, como objetivo de transformá-lo. \\
\hline $\begin{array}{l}\text { Obter diplomas, notas de acordo com o conteúdo transmitido, indo cada vez mais } \\
\text { além; }\end{array}$ \\
\hline $\begin{array}{l}\text { A aprendizagem significativa, envolvendo toda a pessoa, a pesquisa dos conteú- } \\
\text { dos será feita pelos/as alunos/as, que deverão ser capazes de criticá-los, aperfei- } \\
\text { çoá-los e substituí-los caso seja necessário. }\end{array}$ \\
\hline
\end{tabular}

Uma vez elaborados os instrumentos, a aplicação dos questionários para a coleta de dados se deu em forma de Rodas de Conversa, o que fomentou os diálogos e discussões nos encontros. Para Silva e Bernardes (2007), a Roda de Conversa é um profícuo meio para coletar informações, caracterizando-se como uma oportunidade de aprendizagem e exploração de argumentos, sem a exigência de elaborações conclusivas, em que a conversa se desenvolve num clima de informalidade, o que cria possibilidades de diálogos.

Na visão de Figueiredo e Queiroz (2013), a Roda de Conversa é uma metodologia participativa muito interessante, pois favorece a construção de uma prática 
dialógica em pesquisa, o que possibilita o exercício de pensar compartilhado. De acordo com essas autoras, torna-se importante o uso de tal prática no sentido de coletar informações por meio do diálogo.

Como ressalta Freire (1987), uma investigação participativa implica, necessariamente, uma metodologia que não pode contradizer a dialogicidade da educação libertadora. Nesse sentido, ela deve ser dialógica e também conscientizadora, proporcionando, ao mesmo tempo, a compreensão dos temas geradores e a tomada de consciência.

Pensando nessas possibilidades, optamos por tal metodologia que busca, por meio do diálogo, reflexões e discussões de forma intencional, levando-se em consideração os distintos saberes - dos educandos e dos educadores - em que todos dizem a palavra, sem discriminação. Nessa proposta, todas as pessoas têm a oportunidade de expressar o que pensam, o que sentem, além de manifestar suas visões de mundo.

Aqui, especificamente, tratamos das diferentes abordagens do processo de ensinar e aprender como um todo, sejam em relação ao papel do/a aluno/a e do/a professor/a, às expectativas frente à escola, no que ela poderia ser melhorada, a melhor forma de avaliação, de compreender o conhecimento, o que a educação deveria priorizar, bem como o que os/as participantes consideram mais importante no que concerne ao ensinar e aprender.

No decorrer da investigação, foram realizados encontros sistemáticos em oito salas de seis escolas da FUMEC. Os depoimentos dos educandos foram registrados de acordo com os debates e discussões emergidos a partir das leituras prévias de cada questão e de suas alternativas. A organização e condução das Rodas de Conversa foram combinadas entre as/os participantes, que concordaram que, embora muitas respostas parecessem "corretas", deveriam escolher somente uma das alternativas, ou seja, aquela que considerassem mais adequada, conforme suas visões de mundo. Essa proposta foi negociada e aceita por todos as/os integrantes da pesquisa.

\section{EDUCAÇÃO POPULAR - PERSPECTIVAS NA EDUCAÇÃO DE JOVENS E ADULTOS (ANO INICIAIS)}

Entendendo a educação, escolar ou não, como um processo plural, através do qual a raça humana vai construindo seu conhecimento, pode-se inferir que toda educação transforma. Não há ato educativo que não transforme, quer seja de maneira libertadora, quer seja de maneira a retroceder em uma conduta ou concepção. (VASCONCELOS, 2002, p. 47). 
O que nos ensinam e o que aprendem os alunos de EJA em seus processos educativos?

Contribuições da educação popular

Consideramos que, mesmo com diversas dificuldades enfrentadas no processo de ensino e aprendizagem, é possível para educandos e educadores, a partir de práticas pautadas no diálogo, a construção do conhecimento buscando novos sentidos para o mundo.

A Educação Popular requer trabalho, preparação e esforço para o educador popular, não é algo simples, ao contrário, trata-se de uma proposta educativa democrática, crítica, dialógica que exige muito conhecimento e discernimento daquilo que se pretende alcançar.

De acordo com Brandão (2006, p. 43), a Educação de Jovens e Adultos representa a tentativa de superação de uma negação de direitos.

Ao lidar com um menos social, a educação de adultos termina por converter-se em um sinal negativo daquilo que, por oposição a ela, é a educação. Excluídos da escola e defasados do saber escolar, na verdade que a retórica dos discursos oficiais oculta com cuidado, sujeitos das classes populares são para não serem educados regularmente.

Em uma sociedade desigual, à margem da educação seriada, formal, escolar, regular, há diferenças na formação daqueles/as que têm condições de estudar e dos que não tiveram a escolaridade na idade adequada, como acontece na Educação de Jovens e Adultos. Nesse sentido, torna-se fundamental uma prática educativa com qualidade crítica, problematizadora, como apontam os princípios da Educação Popular.

Depois de alguns anos de tropeços, recuos e atropelos, alguns princípios ficaram claros. A Educação Popular é a negação da negação. Não é um "método conscientizador", mas é um trabalho sobre a cultura que faz da consciência de classe um indicador de direções. É a negação de uma educação dirigida "aos setores menos favorecidos da sociedade" ser uma forma compensatória de tornar legítima e reciclada a necessidade política de preservar pessoas, famílias, grupos, comunidades e movimentos populares fora do alcance de uma verdadeira educação. Ela procura ser, portanto, não a afirmação da possibilidade de emergência de uma nova educação "para o povo" - o que importaria a reprodução legitimada de "duas educações" paralelas, condição da desigualdade consagrada - mas a da necessidade da utopia de transformação de todo o projeto educativo a partir do ponto de vista e do trabalho de classe das classes populares. (BRANDÃO, 2006, p. 50).

Educadores e educadoras populares podem e devem afirmar-se em seus desejos, suas visões de mundo, bem como partilhar a certeza de que todos têm o direito de lutar por seus ideais, sonhos, mesmo que estes sejam diferentes. Educadores e 
educadoras populares têm, em si, a realidade como um ponto de partida e de chegada. A prática educativa implica opções, rupturas, decisões, estar com e pôr-se a favor de alguns projetos de sociedade e contra outros.

A Educação Popular jamais separa o ensino de conteúdos do desvelamento da realidade, pois é isso que estimula a organização das classes populares na luta em favor da transformação democrática da sociedade, na superação das injustiças sociais e respeito aos saberes dos educandos na luta por uma boa qualidade de ensino (FREIRE, 2001).

Trabalhamos, na presente investigação, sob a perspectiva freireana de, acima de tudo, valorizar o ser humano como um todo. Partimos do princípio de que a educação deve perseguir a formação cidadã numa perspectiva crítica, buscando uma verdadeira mudança com as/os educandas/os, homens e mulheres excluídos pela sociedade por não saberem ler e escrever e, consequentemente, alijados da possibilidade de ser mais, de superar uma visão ingênua da realidade para um saber crítico em relação ao seu cotidiano.

\section{RESULTADOS E DISCUSSÃO}

Nesse tópico trazemos alguns recortes que ilustram as concepções de ensinar e aprender na EJA I, tomando os resultados da pesquisa em todas as escolas como aporte para as discussões, além de cotejá-los com algumas premissas da Educação Popular.

Os participantes da pesquisa foram mulheres e homens, jovens e adultos que, mesmo com a defasagem em relação aos seus estudos escolares, pensam em seu futuro, têm uma visão própria sobre seu processo de formação e desejam uma educação de qualidade, voltada aos seus interesses. Suas respostas, questionamentos, depoimentos e indagações refletem isso.

Os resultados nos permitem constatar que as/os alunas/os, majoritariamente, desejam uma escola em que seja possível o crescimento recíproco, o respeito pela/o aluna/o e seus saberes. A maioria preconiza que professoras/es e alunas/os devem trabalhar juntos na construção do conhecimento, aproximando-se de uma concepção sociocultural, na qual a EP se encaixaria. Quando foi realizada a leitura da primeira questão: "O que você acha que tem que fazer, como/a aluno/a, para aprender melhor?", uma das respostas foi:

Um lugar onde haja respeito por nós, é o que queremos. 
Por meio dos diálogos com estudantes de EJA, percebemos nitidamente a importância dada ao respeito, ao diálogo, à troca de saberes, o que Paulo Freire (1996, p. 12) sempre enfatizou: "Quem ensina aprende ao ensinar e quem aprende ensina ao aprender. Quem ensina, ensina alguma coisa a alguém".

Outra demanda levantada entre os/as participantes foi a de que:

A professora tem que ser alegre para que o aluno se sinta bem, jamais chegar numa sala de aula triste, com raiva, brava assim deixa o aluno nervoso, com medo, mas se a professora for alegre, o aluno aprende muito mais.

Como acrescenta Paulo Freire (1996, p. 53): “A alegria não chega apenas no encontro do achado, mas faz parte do processo da busca. E ensinar e aprender não podem dar-se fora da procura, fora da boniteza e da alegria". Essas concepções estão nas falas dos nossos/as alunos/as de EJA como também nos ideais da EP. Por que não buscarmos a construção do conhecimento com alegria, esperança no futuro melhor, em que todos tenham direito a um aprendizado de qualidade?

Com relação à segunda questão (“Como você gostaria que fosse a escola?”), ao debatermos sobre uma das alternativas - "Um lugar que controle todos os/as alunos/as, ensinando o jeito certo, premiando quem se comporta melhor", uma das participantes argumentou:

Nossa! Premiar quem se comporta melhor? Que horrivel! Isso é humilhar os outros.

Pela fala da aluna, premiar "os que são melhores" é uma forma de discriminar as/os demais, de impor saberes. Onde fica o papel da Educação se o educador ao invés de promover a solidariedade incentiva a competição? Nós, educadoras/es, podemos e devemos desenvolver, junto ao educando, outras formas de agir e pensar por meio de novas possibilidades de aprendizagem, rever o papel da escola nesse processo, diante de inúmeras alternativas que têm como princípio básico o diálogo associado às reflexões sobre a realidade.

Para a maioria das/os participantes desta pesquisa, a aprendizagem significativa é o que as/os motiva na construção do conhecimento. Isto foi constado quando foi lida a questão: "Como você acha que deve ser a avaliação?".

Primeiro o aprendizado, depois a prova de acordo com o que cada um sabe.

Cada um sabe o que aprendeu...

Dentro das possibilidades de escolhas nas alternativas oferecidas, as/os alunos/ as optaram pela avaliação conjunta mestre/aprendiz, e isso mostra que a maioria 
das/os educandas/os busca a tomada de consciência, criando assim, condições para que se desenvolvam reflexões de forma crítica, comprometidas com a ação, características gerais da abordagem sociocultural, diferentemente da/o professor/a considerada/o detentor/a do conhecimento a quem caberia, unicamente, o poder de avaliar o processo.

Por outro lado, muitas/os indicaram escolhas que se aproximam das concepções comportamentalistas e tradicionais, como a necessidade de reforço, por exemplo, em aulas planejadas. Um exemplo disso ocorreu nos momentos em que se debateu a questão ("Como o/a professor/a deve trabalhar em sala de aula"), tendo como uma das alternativas: "Com muitas atividades planejadas e reforço para verificar se o/a aluno/a realmente aprendeu". Várias respostas se aproximaram do que ilustra a fala a seguir:

Reforço sempre é bom, não somos iguais, uns aprendem muito mais fácil do que outros.

Em nossa compreensão, isso demonstra que os/as alunos/as atribuem grande importância ao papel do/a professor/a, de quem seria a responsabilidade na transmissão de conteúdos e aprendizagem. O mais interessante, quando ouvimos as vozes dos/as alunos/as, é que eles/as não desejam para o processo de ensino e aprendizagem algo inacessível ou que seja difícil de realizar. Ao contrário, querem pequenas atitudes dos/as professores/as e deles/as próprios que possam mudar, para melhor, o processo educativo.

Outra pergunta do questionário foi: "De que forma você acredita que poderia melhorar tanto as maneiras de ensinar quanto de aprender na escola". Quando foi lida a alternativa: "Os alunos devem aceitar a verdade: fazer o que o/a professor/a manda, afinal é ele quem sabe o que é melhor para seus alunos, ele estudou para isso", algumas das respostas mostraram a indignação dos participantes:

Que desaforo professora! Só o professor é o que sabe tudo? Enós onde ficamos?

Tem que respeitar o saber, o saber do aluno.

Nessas falas ficou evidente a crítica à figura do/a professor/a visto/a como aquele/a que "sabe tudo", e a reivindicação de se valorizar as pessoas como aprendizes que são. Partiram do princípio de que todas/os, independente de classe social, escolaridade ou gênero, possuem saberes e esses saberes devem ser respeitados. Como podemos, nós educadoras/es, dizer que somos progressistas se menosprezamos o saber popular? 
Ao ser lida a questão: "Para você o conhecimento é..." algumas/uns alunas/os demonstraram bastante consciência de seu conhecimento, de sua aprendizagem, o que reforça a necessidade de os/as educadores/as, ao pensarem em uma educação transformadora, considerarem e valorizarem profundamente os saberes do grupo. Se estes simplesmente impuserem uma educação que para eles/as é a "correta", a "ideal", não haverá aprendizado significativo, é preciso haver diálogo, reflexão na busca do conhecimento. Nessa questão, a maioria das respostas dos/as alunos/as apontou para a abordagem cognitivista, que enfatiza o conhecimento como uma construção contínua em que o ser humano é considerado um sistema aberto, em etapas de formação em busca de um estágio final nunca alcançado por completo.

A gente nasce aprendendo, morre de velho e nunca acaba de aprender.

Se a gente quiser, a gente muda de vida.

Antes eu não ia à escola e eu não sabia nada, tinha até medo de ir ao supermercado, de comprar as coisas, de andar de ônibus, depois que eu fui à escola, ganhei autonomia, muitas coisas que eu não sabia, agora eu sei.

As respostas dos/as educandos/as de EJA I mostraram haver um consenso acerca da importância de o/a professor/a em desempenhar sua tarefa de preparar boas aulas e de seu papel como alunos/as para que, juntos, possam refletir no intuito de alcançar uma educação libertadora, por meio do diálogo.

Os resultados revelaram o que a educação escolar, muitas vezes, se recusa a enxergar: que há muito conhecimento por parte dos/as alunos/as que, mesmo com pouca afinidade com o conhecimento produzido teoricamente, demonstram discernimento e sensatez em suas respostas na busca do conhecimento, como demonstra ao questionamento de um aluno quando foi lida a questão: "Para você o que a educação deveria priorizar":

A educação seria toda a formação de uma pessoa? Mas de acordo com a escola, ou na vida em geral?

O sujeito respondeu à pergunta com uma indagação, problematizando o tema, buscando o confrontar de saberes e construir conhecimentos. Para a relação ensino e aprendizagem isso é fundamental, tanto para os/as que aprendem, quanto para os/as que ensinam, como diz Barbosa (2009, p.19): "A concepção que fazemos do ensinar e do aprender não pode ser dissociada da concepção do conhecimento e da realidade". 
Quando arguidos sobre o que era importante em relação ao ensinar e o aprender, algumas respostas foram bastante contundentes:

Não quero passar de ano, sem saber, na minha idade o que isso adianta? Quero sim, aprender a falar melhor, a aprender coisa que me dê mais segurança de fazer coisas sem depender de ninguém, isso sim modifica nossa realidade.

Nessa concepção humanista de educação, o/a professor/a não ensina, mas cria condições para que os/as alunos/as aprendam, contribuindo para sua iniciativa, responsabilidade, autodeterminação, discernimento, e com isso construa sua autonomia. A pesquisa dos conteúdos será feita pelos/as alunos/as que deverão ser capazes de criticá-los, até mesmo modificá-los se assim acharem necessários. Além disso, buscam uma aprendizagem significativa capaz de trazer mudanças em sua realidade, respeitando as suas experiências como ponto de partida para o próprio crescimento, independente de diplomas e/ou certificados.

A gente aprende pensando no que a gente faz todos os dias, a vida é uma escola, não precisa de diploma.

As Rodas de Conversa permitiram profícuas reflexões conjuntas, proporcionando uma visão bastante ampla sobre as concepções dos/as alunos/as em relação aos processos de ensinar e aprender.

Consideramos que a Educação Popular abre importantes possibilidades de transformar a prática educativa por meio de uma relação dialógica que supõe troca, não imposição. Assim, "o educador já não é o que apenas educa, mas enquanto educa é educado, em diálogo com o educando, que, ao ser educado, também educa" (FREIRE, 1987, p. 39).

De acordo com Marco Raúl Mejía (2005, p. 25):

A primeira reformulação da Educação Popular atual fixa-se na fidelidade a seus princípios, o primeiro deles é partir da realidade concreta: o capitalismo globalizado e neoliberal não apenas aprofunda as leis básicas do capital (taxa de lucro, acumulação, monopolização e exploração), como também modifica muitas das formas de controle e realização do lucro, significando uma mudança nas regras do jogo. Por essa razão, é necessária uma mudança nas práticas e estratégias dos grupos e atores que sofrem a dominação capitalista da atualidade.

Nessa concepção, faz-se necessário questionar alguns pensamentos que se mostram naturalizados dentro do capitalismo exacerbado que estamos vivendo, em que se valoriza a produtividade na educação, o mérito, o consumo sem limites, a satisfação de desejos imediatos, e principalmente, o acúmulo de capital. Esse 
pensamento hegemônico, imposto pela classe dominante, prega a ideologia de que o indivíduo pode tudo e que para ser bem sucedido tudo depende unicamente de seus esforços, o que faz premente a necessária tomada de consciência para mudar o que está posto. Para muitos/as isso poderia ser considerado utopia. Entretanto, se há algo em que a Educação Popular deve se orgulhar é do seu caráter utópico, rebelde e transformador em denunciar aquilo que é desumano, autoritário, com vistas a desestruturar certas "verdades" sobre as quais se alicerçam as formas de poder existentes ao nosso redor, em nosso mundo.

Em relação a isso, Freire (2001) deixa claro que a utopia está vinculada à conscientização diante da realidade em que vivemos, que não pode haver uma prática educativa sem sonhos, sem intencionalidades. Para ele, no mundo atual as utopias são essenciais, pois é por meio delas que buscamos ações para possíveis mudanças, de forma esperançosa, pacientemente impaciente, que rejeita o conformismo e o fatalismo.

\section{CONSIDERAÇÕES FINAIS}

É importante que seja consagrada a ideia de que não apenas todas as crianças e adolescentes devem ser educados qualitativamente da mesma maneira, como também, através da educação, os "menos favorecidos" devem conquistar condições de acesso ao trabalho e à vida social que, fora da escola, a sociedade oferece com sobras a uns e, com extrema avareza, a outros. (BRANDÃO, 2006, p. 22).

Por meio da pesquisa realizada, pudemos apreender diversas concepções, às vezes até contraditórias, que participantes da Educação de Jovens e Adultos possuem, a partir de distintas indagações: como essas/es alunas/os pensam, quais suas concepções de ensino e aprendizagem em relação ao seu papel como educandas/os, qual seria o papel do/a professor/a, de que maneira é vista a educação, que percepção têm da escola, entre outras.

Em razão disso, da investigação da pesquisa da qual emergiu este artigo, foi possível reforçar a pungente necessidade de uma escuta atenta a nossos/as alunos/as, na procura por saber quais são seus desejos, seus anseios, visões de mundo e buscas, com vistas a um ensino libertador, uma vez que todas e todos nós temos esse direito.

A Educação Popular favorece que aprendizes e mestres possam refletir conjuntamente sobre a aprendizagem, dialogando, problematizando, questionando, rompendo com a verdade estabelecida, única, e rumando para formas de ação mais conscientes e críticas, refletindo sobre os percursos e planejando novos rumos. 
As diferentes concepções de ensino-aprendizagem abordadas no trabalho, apoiadas no referencial de Mizukami (1986), permitiram uma melhor sistematização dos dados sem, entretanto, engessar o conhecimento produzido em uma "teoria fechada", uma vez que as entendemos como sistemas incompletos, no sentido de estarem em permanente elaboração, podendo ou não ser aceitas.

Consideramos de fundamental importância apreender, analisar e discutir opções teóricas existentes em situações de aprendizagem, como o que foi feito em diálogo com os/as alunos/as de EJA. Por meio das Rodas de Conversa, na simplicidade das palavras, pudemos distinguir diferentes epistemes apoiadas em argumentos apoiados em suas vivências, experiências, pontos de vista, que muitas vezes não são levados em conta no âmbito escolar.

Segundo Rosa Maria Torres (1988), em termos gerais, a Educação Popular traz contribuições significativas ao processo pela busca de conhecimento como um espaço e uma ferramenta educativa, a fim de desenvolver a capacidade dos grupos populares para que estes se tornem sujeitos de seu próprio processo educativo e de seu próprio destino, o que faz dela um meio privilegiado para sua libertação cultural, política e social.

A Educação Popular, quando dirigida aos adultos dos setores populares, contribui para a transformação das mentalidades, consciências e atitudes, buscando construir uma nova sociedade, partindo da realidade e refletindo sobre ela no intuito de transformá-la. Para isso a educação deve ser participativa, crítica e dialógica e não contar somente com o/a "professor/a que ensina", mas com a experiência das/ os educandas/os, alimentando, dessa forma, uma construção conjunta de conhecimentos na busca pela emancipação daqueles e daquelas nela envolvidos.

Reforçamos, com este trabalho, nossa crença de que, por meio da Educação Popular, é possível construir uma educação mais humana, igualitária e justa, de modo a contribuir para uma aprendizagem significativa entre Jovens e Adultos. Reafirmamos nossas convicções de que uma prática educativa libertadora pode e deve afinar os sonhos de educandas/os e educadoras/es, mesmo quando estes se mostrem muito diferentes.

Acreditamos, como Freire, que nós educadoras/es, não devemos dizer a palavra, mas sim contribuir para que todas/os ampliemos nossos horizontes. Como afirmou um dos sujeitos da pesquisa, ao ser questionado sobre o que ele esperava dos processos de ensino e aprendizagem: 




Figura 1 - "Ter visão das coisas. Aprendo melhor assim"

Fonte: Arquivo pessoal.

\section{REFERÊNCIAS}

BARBOSA, Severino Antonio. Uma nova escuta poética da educação e do conhecimento: diálogos com Prigogine, Morin e outras vozes. São Paulo: Paulus, 2009.

BRANDÃO, Carlos Rodrigues. O que é educação popular? 3. ed. São Paulo: Brasiliense, 2006.

FIGUEIREDO, A. A. F.; QUEIROZ, Tacinara Nogueira de. A utilização de rodas da conversa como metodologia que possibilita o diálogo. In: SEMINÁRIO INTERNACIONAL FAZENDO GÊNERO 10DESAFIOS ATUAIS DO FEMINISMO. Anais Eletrônicos... Florianópolis, 2013. Disponível em:<http:// www.fg2013.wwc2017.eventos.dype.com.br/resources/anais/20/1373241127_ARQUIVO_ AUTILIZACAODERODASDECONVERSACOMOMETODOLOGIAQUEPOSSIBILITAODIALOGO.pdf>.

FREIRE, Paulo. Política e educação. 5. ed. São Paulo: Cortez, 2001.

. Pedagogia da autonomia: saberes necessários à prática educativa. 25. ed. São Paulo: Paz e Terra, 1996.

. Pedagogia do oprimido. 17. ed. Rio de Janeiro: Paz e Terra, 1987.

MEJÍA, Marco Raúl. Aprofundar na educação popular para construir uma globalização desde o sul. In: PONTUAL, Pedro; IRELAND, Thimoty (Org.). Educação popular na América Latina: diálogos e perspectivas. Brasília: Ministério da Educação/UNESCO, 2005. p. 213-24.

MIZUKAMI, Maria da Graça Nicoletti. Ensino: as abordagens do processo. São Paulo: EPU, 1986. 
PEREIRA, Dulcinéia de Fátima Ferreira; PEREIRA, Eduardo Tadeu. Revisitando a história da educação popular no Brasil. Em busca de outro mundo possível. Revista HistedBr, Campinas, SP, n. 40, p. 72-89, dez. 2010. Disponível em: <http://www.histedbr.fe.unicamp.br/revista/ edicoes/40/art05_40.pdf>. Acesso em: 29 jun. 2014.

SILVA, Petronilha Beatriz Gonçalves; BERNARDES, Nara Maria Guazelli. Roda de conversas excelência acadêmica é a diversidade. Revista Educação, Porto Alegre, RS, v. XXX, n. 61, p. 53-92, jan./mar. 2007. Disponível em: <www.redalyc.org/articulo.oa?id=84806104>. Acesso em: 29 jun. 2014.

TORRES CARRILLO, Alfonso. La educación popular. Trayectoria y actualidad. Bogotá: El Buho Editorial, 2008.

TORRES, Rosa Maria. Discurso e prática em educação popular. Tradução de Américo R. Piovesan. Ijuí, RS, 1988.

VASCONCELOS, Valéria Oliveira de. Bebendo em uma fonte de água fresca. Caminhos para a formação de agentes comunitários. 2002. Tese (Doutorado em Educação) - Centro de Educação e Ciências Humanas, Universidade Federal de São Carlos (UFSCar), São Carlos, SP, 2002.

VASCONCELOS, Valéria Oliveira de; OLIVEIRA, Maria Waldenez de. Educação Popular: uma história, um que-fazer. Educação Unisinos, São Leopoldo, RS, v. 13, n. 2, p. 135-46, maio/ ago. 2009.

\section{Sobre as autoras:}

Keila Mourana Marques Silva: Membro do Grupo de Pesquisa CNPq/UFSCar "Práticas Sociais e Processos Educativos" e do Grupo CNPq/UNISAL "Conhecimento e análise das intervenções na práxis educativa sociocomunitária" (CAIPE). Mestre pelo Programa de Mestrado em Educação do Centro Universitário Salesiano de São Paulo (UNISAL), campus Maria Auxiliadora. Possui especialização em Educação Especial - Novos Paradigmas (2006) e Direito Educacional (2007). Graduação em Licenciatura Plena em Letras pela Faculdade de Filosofia de Passos (1991) e graduação em Pedagogia pela Faculdade de Ciências e Letras Plinio Augusto do Amaral (1995). Professora efetiva da Prefeitura Municipal de Campinas e Fundação Municipal para Educação Comunitária (FUMEC). E-mail: keilamourana@gmail.com.

Valéria Oliveira de Vasconcelos: Possui graduação em Educação Física pela Faculdade de Educação Física de Santo André (1984); mestrado em Educação Especial pela Universidade Federal de São Carlos (1996); doutorado em Educação pela Universidade Federal de São Carlos/Universidade de Salamanca-Espanha (2002) e pós-doutorado pela Universidade Júlio de Mesquita Filho (UNESP/Araraquara). Atualmente 
desenvolve novo estágio de pós-doutorado no Departamento de Ciências Ambientais da Universidade Federal de São Carlos. Participante do Curso de Especialización en Epistemologías del Sur CLACSO- Argentina. Professora do Programa de Mestrado em Educação do Centro Universitário Salesiano de São Paulo (UNISAL)/Americana; pesquisadora do Grupo de Pesquisa CNPq/UFSCar "Práticas Sociais e Processos Educativos" desde 1998, do Grupo de Estudos e Pesquisa em Educação Ambiental (GEPEA-CNPq/ UFSCar) e do Grupo "Conhecimento e análise das intervenções na práxis educativa sociocomunitária” (CAIPE/CNPq)- UNISAL. E-mail: valvasc2013@gmail.com.

\section{Recebido em setembro de 2016.}

\section{Aprovado para publicação em maio de 2017.}


